\title{
Fruit waste pectin in enhancing the establishment of probiotic bacteria
}

\begin{abstract}
The influence of pectin derived from the peels of discarded fruits in enhancing the growth of the health promoting probiotic organisms like Bifidobacterium bifidum and Lactobacillus acidophilus was studied by incorporating the derived pectin in the growth media. It was found that the pectins extracted from the different fruit wastes (apple- Malusdomestica, lemon- Citrus limon, orange- Citrus sinensis) enhanced the $\mathrm{CFU}$ counts of the tested organisms at different $\mathrm{pH}$ ranging from $\mathrm{pH} 2$ to 8 . This clearly indicates that the presence of pectin as prebiotic supports the growth and survival of the probiotics in the gastrointestinal tract at extreme acidic to alkaline conditions. This suggests that waste fruits and vegetable peels can be used as a source of pectin to serve as prebiotics. This serves as an effective means of waste management.
\end{abstract}

Keywords: probiotic bacteria, Bifidobacterium bifidum, Lactobacillus acidophilus, Malusdomestica, Citrus limon, Citrussinensis
Volume I Issue 3 - 2014

\author{
Ananya Sen,' Suba GA Manuel,' Radha D \\ $\mathrm{Kale}^{2}$ \\ 'Department of PG Studies in Life Science, Mount Carmel \\ College, India \\ ${ }^{2}$ Centre for Scientific Research and Advanced Learning, Mount \\ Carmel College, India
}

\begin{abstract}
Correspondence: Suba GA Manuel, Department of PG Studies in Life Science, Mount Carmel College (Autonomous), \#58 Palace Rd,Vasanthnagar, Bangalore-560 052, India, Tel +919535522108, Email subaabraham@rediffmail.com
\end{abstract}

Received: May 13, 2014 | Published: July 03, 2014
Abbreviations: GI, gastrointestinal tract; FOS, fructo-oligosaccharides; GOS, galacto-oligosaccharides; FAO, food \& agriculture organization

\section{Introduction}

The human gastrointestinal (GI) tract contains a variety of microflora including both pathogenic and beneficial bacteria. ${ }^{1}$ Harmful bacteria in the GI tract may cause health problems in the host such as diarrhoea, infections, or liver damage. These bacteria may produce substances that increase the risk of selective growth and activity of certain beneficial bacteria in the colon. ${ }^{2}$ Probiotics and their suitable prebiotics can be designed into food products to improve metabolic activities and stimulate their growth through synergistic effects. ${ }^{3}$

Probiotics should be able to recover and compete with microflora in the colon for nutrients and colonization sites. The beneficial bacteria such as Bifidobacteria and Lactobacilli can promote health of host by inhibiting the growth of these harmful bacteria, stimulating the immune system, and enhancing the digestion and absorption of essential nutrients such as short chain fatty acids. ${ }^{2}$ Certain species of Lactobacillus and Bifidobacteria have been used as probiotic supplements in food products to provide better microbial balances in the GI tract and consequently improve the health., ${ }^{4,5}$ However, probiotic applications are limited because these bacteria are likely to be in a stressed state when they reach the colon due to exposure to diverse barriers in the host such as gastric acid and bile acids. ${ }^{2,6}$

Prebiotics are normally commercially extracted from fruits and vegetables through methods such as enzymatic hydrolysis of polysaccharides from dietary fibers or starch. Potential prebiotic carbohydrates include fructo-oligosaccharides (FOS), galactooligosaccharides (GOS), lactulose, lactosucrose, soybean oligosaccharides, iso-maltooligosaccharides, palatinose, xylooligosaccharides, and gluco-oligosaccharides., ${ }^{1,7}$ HernandezHernandez et al., ${ }^{8}$ have shown that prebiotic carbohydrates can enhance the survival of beneficial probiotic bacteria during exposure to gastric conditions. Prebiotics are food ingredients which are indigestible in the human upper GI tract and reach the colon to positively influence the health of the host by selectively promoting the growth and activity of certain beneficial bacteria in the colon. ${ }^{2}$ Probiotics and their suitable prebiotics can be designed into food products to improve metabolic activities and stimulate the growth of the probiotic bacteria through their synergistic effects. ${ }^{3}$ However, pectins have been reported to be able to reduce serum cholesterol in both rats and humans ${ }^{9}$ and are thought to have anti-carcinogenic effects. ${ }^{10}$ Pectin and pectic oligosaccharides have been shown to induce apoptosis in human colonic adenocarcinoma cells. ${ }^{11}$ Using prebiotics and probiotics in combination is often described as a symbiotic. The United Nations Food \& Agriculture Organization (FAO) has recommended the term synbiotictobe used only when the net health benefit is synergistic. Alternatively the prebiotic must support the increase in the population and functioning of the associated probiotic organism. ${ }^{12}$

The partially purified pectins extracted from the fruit peels of apple (Malusdomestica), lemon (Citrus limon) and orange (Citrus sinensis), were considered in the present study to find out their effect on the growth and survival of probiotic bacteria at different $\mathrm{pH}(2,6$, 7 and 8 ). To represent the gastric acidity, control conditions, and the alkaline conditions in the intestine.

\section{Methods and materials}

\section{Culture acquisition}

Starter culture of Lactobacillus acidophilus was procured from Microbial Type Culture Collection and Gene Bank Institute of Microbial Technology, Chandigarh (MTCC number 10307) and the culture of Bifidobacterium bifidum from the Department of Dairy Microbiology, Dairy Science College UAS, Bangalore. Probiotic strains were maintained individually in sterile MRS (Himedia) (De Man, Rogosa and Sharpe) broth at $37^{\circ} \mathrm{C}$ for 4 hours, and then refrigerated at $4^{\circ} \mathrm{C}$. Subculturing was carried out every 7 days.

\section{Determination of growth parameters of probiotic bacteria at different $\mathrm{pH}$}

Probiotic bacteria were individually inoculated into MRS broth, 
adjusted to $\mathrm{pH} 2$ with $0.1 \mathrm{~N}$ hydrochloric acid and for $\mathrm{pH} 7$ and 8 with $0.1 \mathrm{~N}$ Sodium hydroxide. $\mathrm{pH} 6$ served as control. They were incubated at $37^{\circ} \mathrm{C}$ for 2 hours. After incubation the cultures were serially diluted $10^{-4}, 10^{-5}$, and $10^{-7}$ were pour plated on MRS agar. They were incubated at $37^{\circ} \mathrm{C}$ for 48 hours. After 48 hours the colonies were enumerated by using colony counter. The experiment was replicated five times for each parameter.

\section{Extraction of crude pectin from the peels of apple, carrot, lemon and orange}

The peels were washed and blended using distilled water in the ratio of 1:1.5, acidified with lime juice to $\mathrm{pH} 2$ and autoclaved. The mixture was cooled and filtered through cheese cloth. The filtrate was mixed with iso-propyl alcohol in the ratio 1:1 and refrigerated overnight. This mixture was centrifuged at $2000 \mathrm{rpm}$ for 10 minutes. The residue (pectin) was dried at $48^{\circ} \mathrm{C}$.

\section{Determination of growth parameters of probiotic bacteria with different prebiotic samples at different $\mathrm{pH}$}

The samples of pectin from apple, lemon, orange, and commercial pectin were added to the broth at $\mathrm{pH} \mathrm{2,6,7}$ and 8 along with the bacterial culture, and incubated at $37^{\circ} \mathrm{C}$ for 2 hours. After the incubation period, the cultures were serially diluted and the dilution $10^{-7}$ (for L. acidophilus) and $10^{-4}$ (for B. bifidum) were pour plated on MRS agar and then incubated at $37^{\circ} \mathrm{C}$ for 48 hours. After 48 hours the colonies were enumerated using colony counter.

\section{Results and discussion}

L. acidophilus showed a higher number of colonies as compared to $B$. bifidum at all the $\mathrm{pH}$ levels indicating that $L$. acidophilus exhibited better increase in CFU compared to B. bifidum. L. acidophilus at different $\mathrm{pH}$ where in maximum growth of colonies was at $\mathrm{pH} 6$ and least at $\mathrm{pH} 2$ (Table 1). This indicates that although these organisms do not survive at $\mathrm{pH} 6$ under acidic conditions, the growth was still substantial. The colony count at $\mathrm{pH} 8$ indicated that they remained unaffected by alkaline situations. One way ANOVA showed that there was clear indication of effect of $\mathrm{pH}$ on the growth of these organisms. The findings with L. acidophilus corresponded to that of Gomes and Malcata ${ }^{13}$ who in their study showed that acid tolerance of L. acidophilus varied from $0.3 \%$ to $1.9 \%$ titratable acidity, with an optimum $\mathrm{pH}$ lying at $5.5 \pm 6.0$. This indicates that L. acidophilus has evolved some mechanisms for tolerance to wide ranges of $\mathrm{pH}$ in the gut as a result of which it does not require any additional protective mechanisms.

B. bifidum also showed the highest $\mathrm{CFU}$ at $\mathrm{pH} 6$ which is in accordance to the growth characteristics of MRS media (optimum $\mathrm{pH}$ being $6.5 \pm 0.2$ ). The growth at $\mathrm{pH} 2$ was nil indicating that in order to survive the acidic $\mathrm{pH}$ these organisms require protective mechanisms. The growth at $\mathrm{pH} 7$ and $\mathrm{pH} 8$ was higher compared to $\mathrm{pH} 2$ and this was expected as these organisms are typical flora of the alkaline intestine (Table 2). Furthermore, one way ANOVA showed that $\mathrm{pH}$ had a significant effect on the growth of these organisms. The growth characteristics of $B$. bifidum were in accordance with the results obtained by Gomes and Malcata ${ }^{13}$ and $\mathrm{O}^{\text {'May et al., }}{ }^{14}$ stating that the optimum $\mathrm{pH}$ for growth of $B$. bifidum is 6 , with virtually no growth at $\mathrm{pH} 4.5$ or below or at $\mathrm{pH} 8.0$ or above.

The pectin samples were found to be potential prebiotic agent that increased the growth of B. bifidum (Table 3 ) as compared to $L$. acidophilus (Table 4). The growth in B. bifidum and L. acidophilus was highest at $\mathrm{pH} 6$ in all the experimental conditions. It was observed that the growth of $B$. bifidum was highest in presence of apple pectin at $\mathrm{pH} 2$ and that of orange pectin at $\mathrm{pH} 6,7$ and 8 at $10^{-4}$ dilution (Table 3 ). The growth of $L$. acidophilus was highest with pectin from apple at $\mathrm{pH} 2$, with orange pectin at $\mathrm{pH} 6$, apple pectin at $\mathrm{pH} 7$ and apple pectin at $\mathrm{pH} 8$ at $10^{-7}$ dilution (Table 4). Two way ANOVA with interaction was also calculated and the results were found to be statistically significant.

Table I Growth of L. acidophilus at different $\mathrm{pH}$ at various dilutions $(\mathrm{n}=5)$

\begin{tabular}{llll}
\hline & \multicolumn{2}{l}{ Dilution } & \\
\cline { 2 - 4 } $\mathrm{pH}$ & $10^{-4}$ & $10^{-5}$ & $10^{-7}$ \\
\hline 2 & $631.2 \pm 30.38$ & $142.8 \pm 19.06$ & $3.6 \pm 0.89$ \\
6 & $2265.6 \pm 78.26$ & $829.6 \pm 36.07$ & $14.2 \pm 1.92$ \\
7 & $2258.4 \pm 52.05$ & $535.2 \pm 68.67$ & $7.8 \pm 1.30$ \\
8 & $1420.8 \pm 83.88$ & $622.4 \pm 74.65$ & $15 \pm 1.58$ \\
\hline
\end{tabular}

*The results are statistically significant

Table 2 Growth of $B$. bifidum at different $\mathrm{pH}$ at various dilutions $(\mathrm{n}=5)$

\begin{tabular}{llll}
\hline & \multicolumn{2}{l}{ Dilution } & \\
\cline { 2 - 4 } $\mathrm{pH}$ & $10^{-4}$ & $10^{-5}$ & $10^{-7}$ \\
\hline 2 & $\mathrm{Nil}$ & $\mathrm{Nil}$ & $\mathrm{Nil}$ \\
6 & $416 \pm 29.52$ & $69.8 \pm 2.68$ & $2.8 \pm \mathrm{I} .3$ \\
7 & $118.6 \pm 41.87$ & $10.2 \pm \mathrm{I} .78$ & $\mathrm{Nil}$ \\
8 & $183.2 \pm 21.79$ & $25.8 \pm 6.76$ & $10.8 \pm 3.7$ \\
\hline
\end{tabular}

*The results are statistically significant

Thus in the case of B. bifidum, it was seen that each pectin sample enhanced the number of colony forming units to a very great extent. At $\mathrm{pH} 2$ the growth enhancement was approximately 350 fold indicating that pectin might provide protection against the acidic $\mathrm{pH}$ in the stomach. Furthermore, at $\mathrm{pH} 6$ the growth of two fold increase, at $\mathrm{pH} 7$ it was seven folds and at $\mathrm{pH} 8$ it was of five folds (Table 3). This indicates that pectin is readily metabolized by B. bifidum and as a result their growth rate is greatly enhanced. Various growth responses of the bacteria to the pectin samples at various $\mathrm{pH}$ was also observed by Palframan et al. ${ }^{15}$ The fermentation carried out at different $\mathrm{pH}$ will have direct effect on the substrate metabolism because of the change in enzyme activity at different $\mathrm{pH}$. However, they found that in general, the pectin samples increased the growth of Bifidobacteria. Similar results were also reported by Olano-Martin et al., ${ }^{11}$ who investigated the effect of various pectin and pectin-oligosaccharides on Bifidobacteria.

However, pectin was able to increase the growth of L. acidophilus only to a certain extent in comparison to high growth in B. bifidum. At $\mathrm{pH} 2$ there was very little or no response to enhancement of growth indicating that pectin might not provide any protection against the acidic $\mathrm{pH}$ in the stomach. This result was different from the findings of Nazzaro et al. ${ }^{16}$ They had found that the initial growth of Lactobacillus at acidic $\mathrm{pH}$ in the presence of pectin significantly improved the growth of the bacteria. However, at $\mathrm{pH} 6$ the growth enhancement was four folds which were higher than in the case of B. bifidum. At $\mathrm{pH}$ 7 and $\mathrm{pH} 8$ there was hardly any increase in growth which indicates 
that these organisms do not require pectin as growth enhancing molecule. Pectin is already being used in microencapsulation of probiotics $^{17}$ in order to create more effective delivery systems for the probiotic bacteria. However, it has not been as well characterized as other prebiotics such as inulin whose prebiotic mechanisms have been effectively studied. Further understanding of the protective mechanisms conferred by pectin will further enhance the numerous beneficial effects of probiotics. This will be useful because fruit and vegetable peels are rich sources of pectin and can thus be used to produce pectin in an efficient manner reducing the amount of vegetable waste. The potential of fruit and vegetable waste is not only limited to the production of value added products but could also be utilized in enhancing the growth of the probiotic bacteria and can eventually bring down the level of contamination in the environment.

Table 3 Growth of B.bifidum at different $\mathrm{pH}$ with different pectin samples at $10^{-7}$ dilution $(n=5)$

\begin{tabular}{lllll}
\hline Sample & pH 2 & pH 6 & pH 7 & pH 8 \\
\hline Apple & $523 \pm 5.73$ & $586.4 \pm 45.13$ & $683.2 \pm 7.69$ & $852 \pm 16.49$ \\
Lemon & $350.4 \pm 39.04$ & $743.2 \pm 44.13$ & $881.6 \pm 33.66$ & $1152 \pm 21.73$ \\
Orange & $360.6 \pm 52.15$ & $752 \pm 54.04$ & $953.6 \pm 67.76$ & $1276.4 \pm 55.72$ \\
Commercial Pectin & $764.8 \pm 20.08$ & $2964 \pm 22.45$ & $1072.8 \pm 16.83$ & $1056.8 \pm 36.81$ \\
\hline
\end{tabular}

*The results are statistically significant

Table 4 Growth of $L$. acidophilus at different $\mathrm{pH}$ with different pectin samples at $10^{-4}$ dilution $(n=5)$

\begin{tabular}{lllll}
\hline Sample & $\mathbf{p H ~ 2}$ & $\mathbf{p H ~ 6}$ & $\mathbf{p H ~ 7}$ & $\mathbf{p H ~ 8}$ \\
\hline Apple & $5.4 \pm 0.55$ & $48.8 \pm 12.48$ & $9.6 \pm 0.55$ & $22.2 \pm 3.03$ \\
Lemon & $2.4 \pm 0.57$ & $55.4 \pm 6.19$ & $8.4 \pm 0.55$ & $18.4 \pm 1.82$ \\
Orange & $1.6 \pm 0.55$ & $77.4 \pm 1.67$ & $9.2 \pm 0.45$ & $16.2 \pm 2.17$ \\
Commercial Pectin & $3.8 \pm 0.45$ & $60.4 \pm 3.65$ & $10.2 \pm 0.45$ & $17.8 \pm 1.10$ \\
\hline
\end{tabular}

*The results are statistically significant

\section{Acknowledgements}

None.

\section{Conflict of interest}

Author declares that there is no conflict of interest.

\section{References}

1. Manning ST, Gibson GR. Prebiotics. Best Practice \& Research Clinical Gastroenterology. 2004;18(2):287-298.

2. Gibson GR, Roberfroid MB. Dietary modulation of the human colonic microbiota: introducing the concept of prebiotics. J Nutr. 1995;125(6):1401-1412.

3. Zanoni S, Pompei A, Cordisco L, et al. Growth kinetics on oligo- and polysaccharides and promising features of three antioxidative potential probiotic strains. J Appl Microbiol. 2008;105(5):1266-1276.

4. Fuller R. Probiotics in man and animals. $J$ Appl Bacteriol. 1989;66(5):365-378.

5. Goldin BR, Gorbach SL. Probiotics for humans. In: Fuller R, editor Probiotics the scientific basis. London: Chapman and Hall; 1992. p. 355-376.

6. Pochart P, Marteau P, Bouhnik Y, et al. Survival of bifidobacteria ingested via fermented milk during their passage through the human small intestine: an in vivo study using intestinal perfusion. Am J Clin Nutr. 1992;55(1):78-80.

7. Gibson RG, Berry OP, Rastall RA. Prebiotics: New developments in functional foods. Oxford: Chandos Publishing Limited; 2000.

8. Hernandez-Hernandez O, Muthaiyan A, Moreno FJ, et al. Effect of prebiotic carbohydrates on the growth and tolerance of Lactobacillus. Food Microbiol. 2012;30(2):355-361.
9. Gulfi M, Arrigoni E, Amado R. Influence of structure on in vitro fermentability of commercial pectins and partially hydrolysed pectin preparations. Carbohydrate Polymers. 2005;59(2):247-255.

10. Scheppach W, Bartram HP, Richter F. Role of short-chain fatty acids in the prevention of colorectal cancer. Eur $J$ Cancer 1995;31A(7-8):1077-1080.

11. Olano-Martin E, Rimbach GH, Gibson GR, et al. Pectin and pectic-oligosaccharides induce apoptosis in in vitro human colonic adenocarcinoma cells. Anticancer Res. 2003;23(1A):341-346.

12. Pineiro M, Asp NG, Reid G, et al. FAO technical meeting on prebiotics. J Clin Gastroenterol. 2008;42(Suppl 3Pt 2):S156-S159.

13. Gomes AMP, Malcata FX. Bifidobacterium spp. and Lactobacillus acidophilus: biological, biochemical, technological and therapeutical properties relevant for use as probiotics. Trends in Food Science \& Technology. 1999;10:139-157.

14. O’May GA, Reynolds N, Macfarlane GT. Effect of $\mathrm{pH}$ on an in vitro model of gastric microbiota in enteral nutrition patients. Appl Environ Microbiol. 2005;71(8):4777-4783.

15. Palframan RJ, Gibson GR, Rastall RA. Effect of $\mathrm{pH}$ and dose on the growth of gut bacteria on prebiotic carbohydrates in vitro. Anaerobe. 2002;8(5):287-292.

16. Nazzaro F, Fratianni F, Nicolaus B, et al. The prebiotic source influences the growth, biochemical features and survival under simulated gastrointestinal conditions of the probiotic Lactobacillus acidophilus. Anaerobe. 2012;18(3):280-285.

17. Aquilah NS, Akhiar M. Enhancement of probiotic survival by microencapsulation with alginate and prebiotics. Basic Biotechnology. 2010;6:1-5. 